\title{
Erratum to: An in silico biomechanical analysis of the stent-esophagus interaction
}

\author{
Mathias Peirlinck $^{1}$ (1) - Nic Debusschere ${ }^{1} \cdot$ Francesco Iannaccone $^{1} \cdot$ \\ Peter D. Siersema ${ }^{2}$ - Benedict Verhegghe ${ }^{1}$ - Patrick Segers ${ }^{1}$ - Matthieu De Beule ${ }^{1,3}$
}

Published online: 20 September 2017

(C) Springer-Verlag GmbH Germany 2017

\section{Erratum to: Biomech Model Mechanobiol DOI 10.1007/s10237-017-0948-9}

In the original publication of the article, Tables 2 and 3 were published with error. The correct tables are provided below (Tables 2,3). The original version of the article has also been corrected.

Table 2 Calibration friction coefficient by comparison of measured and simulated foreshortening recovery ratios (FRR) of the EllaBD252025-100 stent (percentages reflect $\triangle F R R$ difference in elastic recovery between experiment and simulation)

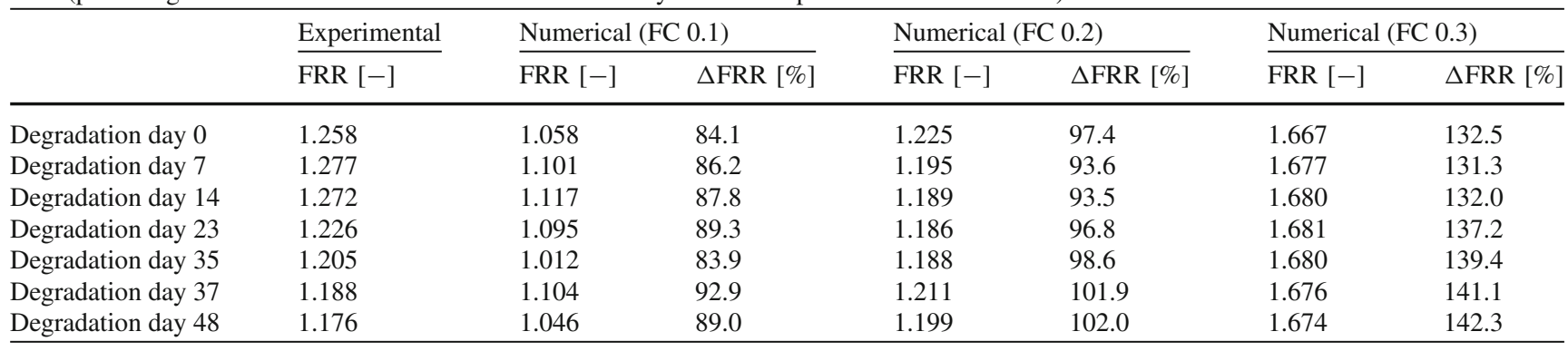

$\mathrm{FRR}=\frac{L_{\text {precrimp }}}{L_{\text {postcrimp }}}[-] ; \quad \Delta \mathrm{FRR}=\frac{\mathrm{FRR}_{\text {experimental }}}{\mathrm{FRR}_{\text {numerical }}}[\%]$

The online version of the original article can be found under https:// doi.org/10.1007/s10237-017-0948-9.

Mathias Peirlinck

mathias.peirlinck@ugent.be

1 Biofluid, Tissue and Solid Mechanics for Medical Applications Lab (IBiTech, bioMMeda), Ghent University, Gent, Belgium

2 Department of Gastroenterology and Hepatology, Radboud University Medical Center, Nijmegen, The Netherlands

3 FEops nv, Gent, Belgium 
Table 3 Fitted constitutive parameters

\begin{tabular}{|c|c|c|}
\hline & \multicolumn{2}{|c|}{ Mucosa (M) } \\
\hline$\mu_{0}(k P a)$ & \multicolumn{2}{|c|}{0.09} \\
\hline & \multicolumn{2}{|c|}{ Submucosa (SM) } \\
\hline$\mu_{0}(k P a)$ & \multicolumn{2}{|c|}{0.09} \\
\hline$\alpha\left(^{\circ}\right)$ & \multicolumn{2}{|c|}{50.4} \\
\hline$k_{1}(k P a)$ & \multicolumn{2}{|c|}{0.61} \\
\hline$k_{2}$ & \multicolumn{2}{|c|}{1.40} \\
\hline$\kappa$ & \multicolumn{2}{|c|}{0.001} \\
\hline & \multicolumn{2}{|c|}{ Interfacial Layer (IF) } \\
\hline \multirow[t]{2}{*}{$\mu_{0}(k P a)$} & \multicolumn{2}{|c|}{0.009} \\
\hline & $\begin{array}{c}\text { Inner Muscularis } \\
\text { Externa (IME) }\end{array}$ & $\begin{array}{c}\text { Outer Muscularis } \\
\text { Externa (OME) }\end{array}$ \\
\hline$\mu_{0}(k P a)$ & 0.17 & 0.17 \\
\hline$\alpha\left(^{\circ}\right)$ & 0.0 & 90.0 \\
\hline$\mu_{s m c}(\mathrm{kPa})$ & 7.16 & 7.16 \\
\hline$u_{r s 0}$ & 0.1 & 0.1 \\
\hline$a_{0}$ & 0.5 & 0.4 \\
\hline$c(\mathrm{~mm} / \mathrm{s})$ & 80.0 & 80.0 \\
\hline$\Delta L(m m)$ & 40.0 & 40.0 \\
\hline$t_{0}(s)$ & 0.25 & 0.0 \\
\hline
\end{tabular}

